\title{
New Elementary Curricula and Teachers
}

\section{Fatma HAZIR BIKMAZ*}

\begin{abstract}
The main objective of this article is to establish some issues that are frequently repeated in the new elementary school curricula in Turkey in 2005-2006 school year, which can lead to misunderstandings by teachers; and to argue why they may lead to misunderstandings together with justifications. Certain matters have been examined below, and these have been repeated frequently throughout the program change process, with a possibility to lead to misunderstanding by teachers. The first one has to do with individual differences. The others are meaning of active learning, the usage of traditional measurement and evaluation techniques, teachers' subject knowledge and work load. All interest and emphases in curriculum changes is focused on the change itself, rather than how the change will be introduced. In order to ensure that this change takes place at the desired level, long-term training courses that allow participation and that take into account the facts of our country must be planned and implemented for teachers. Within this process, existing in service training must be considered seriously and rendered more efficient.
\end{abstract}

Key words: Teacher, teacher education, curriculum, curriculum reform

*Asist. Prof. Dr., Ankara University, Faculty of Educational Sciences.

bikmaz@education.ankara.edu.tr 


\section{SUMMARY}

Significance and purpose: In the recent years very rapid changes are being experienced in the education system in Turkey. During this change process, one of the most controversial issues was the change introduced in the elementary school curricula. A significant change was introduced in the approach to curriculum development, and it was a radical shift from a teacher-subject based approach to student-based approach. The main objective of this article is to establish some issues that are frequently repeated in the new elementary school curricula in Turkey in 2005-2006 school year, which can lead to misunderstandings by teachers; and to argue why they may lead to misunderstandings together with justifications.

The most note-worthy point in the discussions around the implementation of new curricula is the fact that the teachers were not informed properly during this process. In order for the elementary school teachers who cannot receive sufficient training support, and from whom significant tasks are expected - particularly the classroom teachers - to be able to reflect this change to their classes, first they need to well grasp the conceptual infrastructure of the change. It is natural for teachers who are faced with tens of new concepts in a short time to encounter certain difficulties. Certain matters have been examined below, and these have been repeated frequently throughout the program change process, with a possibility to lead to misunderstanding by teachers. The first one has to do with individual differences.

Taking into account the individual differences during the teachinglearning stage is not possible only by a differentiation in methods. Taking into account individual differences not only means employing different methods, techniques or strategies during the teaching-learning process or to carry out different, but also to differ in our expectations from the students.

Active learning is not only to carry out activities. The teachers that have proceeded in accordance with the traditional system may think that in the active learning process, no lectures will be given, and that the established acquisitions will only be reached through activities. However, during the effective learning process, the teacher may use the lecture method when necessary. Furthermore, based on the structure of new curricula, the teachers may take as the starting point the establishment of the relevant activities rather than the concepts/themes they plan the students to acquire during the teaching-learning process. They may consider the chosen or the developed activities with a sequence agreed in the classroom as a process in accordance with the constructivist approach. However, the main objective of the 
activities carried out during the process is to improve understanding of the theme or the concept.

Active learning does not mean that the students are active only in the physically or the socially during the teaching-learning process. In active learning, an effective participation of the student in the learning process is the issue. Any activity that will activate the student in the mentally sense will enable effective learning.

In the new curriculum approach, the teacher will require strong subject knowledge. In the new curriculum approach, the teacher is defined as the person who guides the teaching-learning process, who guides the student and who prepares an effective learning atmosphere. In order to carry out these responsibilities in an effective manner, the teacher will need strong subject knowledge despite the contrary belief.

For the new curricula, traditional measurement and evaluation techniques may be employed in addition to the new techniques for measurement and evaluation. The emphasis of the measurement and evaluation of the new curricula has shifted from the approach of establishing the outcome of the learning, to establishing what the student has acquired during the learning process. However, this does not mean that traditional measurement techniques will not be employed at all, and no evaluation will be made at the end of the learning process.

Planning a learning process in line with the new curriculum approach and to implement this will further increase the work load of the teachers. It is now obligatory for the teachers to be more organised in order to be able to carry out different educational tasks emphasized by new measurement and evaluation approaches, to design a more activity oriented, teaching-learning process based on preconception and individual differences, and to actualise these; and they also need a close cooperation with their colleagues.

Conclusion: All interest and emphases in curriculum changes is focused on the change itself, rather than how the change will be introduced. In order to ensure that this change takes place at the desired level, long-term training courses that allow participation and that take into account the facts of our country must be planned and implemented for teachers. Within this process, existing in service training must be considered seriously and rendered more efficient. In training curricula that will be carried out in accordance with the new approach, joint projects must be designed with universities; and also the assistance of the universities must be sought for in training teachers. 


\section{Yeni İlköğretim Programları ve Öğretmenler}

\section{Fatma HAZIR BIKMAZ*}

ÖZ: Bu çalışmanın amacı Türkiye' de 2005-2006 öğretim yılında ülke genelinde uygulanmasına başlanan yeni ilköğretim programlarında adeta birer slogan gibi sıkça tekrarlanan ve öğretmenler tarafından yanlış anlaşılmaya neden olabilecek bazı konuları belirlemek ve bunların neden yanlış anlaşılabileceğini gerekçeleriyle ortaya koymaktır. Program değişim sürecinde adeta birer slogan gibi sıkça tekrarlanan ve öğretmenler tarafından yanlış anlaşılmaya neden olabilecek konular şöyledir. Bireysel farklılıkları dikkate almak, etkin öğrenmenin anlamı, geleneksel ölçme değerlendirme yaklaşımlarının yeni programlardaki yeri, ögretmenlerin alan bilgisi ihtiyacı ve iş yüklerinin durumu. Program değişiminde bütün ilgi ve dikkat değişimin nasıl yapılacağından çok değişimin kendisine odaklanmıştır. Bu değişimin istenilen düzeyde gerçekleşmesi için daha uzun soluklu, katılımc1 ve ülkemizin gerçeklerine uygun bir öğretmen eğitimi planlanmalı ve uygulanmalıdır. Bu süreçte mevcut hizmet içi eğitim uygulamalarının da ciddi olarak ele alınması ve daha verimli hale getirilmesi gerekmektedir.

Anahtar sözcükler: Öğretmen, öğretmen eğitimi, öğretim programı, program reformu

\section{GİRIŞ}

Türk eğitim sisteminde son yıllarda çok hızlı değişimler yaşanmaktadır. $\mathrm{Bu}$ değişim sürecinde üzerinde en çok tartışılan konulardan biri ilköğretim

Yrd. Doç. Dr., Ankara Üniversitesi, Eğitim Bilimleri Fakültesi 
programları olmuştur. Aslında programlardaki bu değişim sadece Türkiye'de değil birçok gelişmiş ve gelişmekte olan ülkede de yaşanmaktadır. Özellikle 1980-1990'l1 yıllar ABD, Avusturalya, İngiltere, Hollanda, Çin, Rusya, Fransa, İspanya, Güney Afrika ve Malezya vb. gibi birçok ülkenin eğitim sistemlerinde reform hareketini başlattığı yıllar olmuştur. Dünyada eğitim alanında yaşanan bu reform /değişim dalgası bilgi toplumuna geçişin gerekli kıldığı değişimler ve özellikle global yarışta söz sahibi olabilmek üzere ülkelerin insan kaynaklarını geliştirme zorunluluğundan kaynaklanmıştır.

Özellikle eğitim programlarındaki değişimin odağına öğrencilerin global farkındalığını arttırma, problem çözme, iletişim ve global pazarda gerekli olacak yabancı dil becerilerini geliştirme gibi uluslararası arena da geçerli olacak beceriler alınmıştır (Law, 2004). Başka bir deyişle bu süreçte eğitim global becerilerin geliştirilmesinde en önemli araç olarak görülmüştür (Marginson,1999).

Yukarıda sıralanan becerileri eğitim sistemlerinin mevcut yapısıyla geliştirmenin mümkün olamaması, program geliştirme yaklaşımında önemli bir değişimin yaşanmasına neden olmuş ve öğretmen- konu merkezli anlayıştan öğrenci merkezli anlayışa doğru radikal bir değişime gidilmiştir (Gough, 1999; Smerdon, Burkam \& Lee, 1999; Boyd, 2000; Sani, 2000). Bu değişim sürecinde UNESCO, Dünya Bankası, Avrupa Konseyi, Uluslararası Para Fonu gibi pekçok uluslar arası kuruluş aracılık rolü üstlenmiştir. Eğitim reformu/ değişimi bazı ülkelerde isteğe bağlı olarak bazı ülkelerde ise dıştan bir zorlama ile başlatılmıştır.

Pekçok ülkede reform sürecinin üzerinden yıllar geçmiş olmasına rağmen arzulanan değişimin uygulamaya yansıtılması konusunda genel bir başarısızlık yaşanmaktadır (Harlen, 1997; Labaree, 1999; El-Sheik Hasan, 2000; Enderlin-Lampe, 2002; Zajda, 2003; Flouris \& Pasias, 2003; Elkind, 2004; Pinto, 2004). Bu başarısızlıkta pekçok faktör etkili olmuştur. Özellikle gelişmekte olan ülkeler uygulayacakları eğitim programı modellerini gelişmiş ülkelerden aynen almaktadır.Bu durum programın uygulamadaki başarısını doğrudan etkileyecek pek çok koşulun yeterince dikkate alınmaması gibi bir sonuca neden olmaktadır. Ülkelerin farklı sosyokültürel, ekonomik özellikleri ile öğrenmeyi etkileyen psiko-sosyal faktörler iyi analiz edilmediği ve bu özelliklere dayalı özgün bir düzenleme yapılmadığı sürece eğitim reformlarında başarıdan söz etmek güçleşmektedir (Rogan \& Grayson, 2003). Ayrica reformun uygulayıcilar tarafindan yeterince anlaşılamaması da uygulamadaki başarıyı etkileyen önemli bir faktördür. Son yıllarda eğitim alanında gerçekleştirilen reformların uygulamaya yansıtılmasında yaşanan başarızılığın belki de en temel nedeni, bu süreçte ana uygulayıcı olan öğretmenin eğitiminin ihmal edilmiş olmasıdır. Ayrıca 
öğretmenlerin kısa bir süre içinde yeterli eğitimi almadan öğretmen-konu merkezli anlayıştan öğrenci merkezli anlayışa geçmelerini sağlamanın oldukça güç olması da başka bir neden olarak gösterilmektedir.

$\mathrm{Bu}$ çalışmanın amacı Türkiye'de 2005-2006 öğretim yılında uygulamaya konulan yeni ilköğretim programlarında sıklıkla tekrar edilen ve öğretmenler tarafından yanlış anlaşılmaya neden olabilecek bazı konuları belirlemek ve bunların neden yanlış anlaşılabileceğini gerekçeleriyle ortaya koymaktır. $\mathrm{Bu}$ amaçla öncelikle ilköğretim programlarında yapılan değişimin arka planı kısaca ele alınmış, bu süreçte öğretmenlerin yanlış anlaması muhtemel olan konular tartışılmıştır.

\section{İlköğretim Programlarının Değişimi}

Türkiye'de yaşanan program değişiminin temeli 1990 yılında Dünya Bankası ve Türkiye arasında imzalanan bir protokole dayanmaktadır. Milli Eğitimi Geliştirme Projesi olarak bilinen bu proje ile ilk ve orta öğretimin niteliğinin arttırılması, öğretmen eğitiminde kalitenin yükseltilmesi ve yeni yönetim stratejilerinin geliştirmesi amaçlanmıştır (MEB, 1999). Son yıllarda yaşadığımız değişim ise 2000 yılında Avrupa Konseyi ile Türkiye arasında imzalanan "Temel Eğitime Destek Projesi” kapsamında gerçekleştirilmiştir.

Kamuoyuna bir reform olarak duyurulan, altı ay gibi oldukça kısa bir süre içinde hazırlanan ilköğretim programları (Hayat bilgisi 1-3, Sosyal bilgiler 4-5, Fen ve Teknoloji 4-5, Matematik 1-5, Türkçe 1-5) Türkiye'nin farklı bölgelerinde yer alan 9 pilot ilden seçilen 120 ilköğretim okulunda bir y1l süre ile denenmiştir. 2005-2006 öğretim yılında ise bu programlar ülke genelinde uygulanmaya başlanmıştır. İlköğretim programlarında yapılandırmacı yaklaşımın temel alındığı ve buna göre öğrenci merkezli, etkinlik temelli bir öğretme-öğrenme sürecinin hedeflendiği belirtilmiştir (MEB, 2005).

Öğrenmenin doğasını açıklayan bir epistemoloji ya da felsefi bir açıklama olarak tanımlanan yapılandırmacılık (Richardson, 1997; Simpson, 2002), son yirmi yıldır eğitim alanında yapılan çalışmaları ve araştırmaları derinden etkilemiştir (Matthews, 1998; Tsai, 1998). Yapılandırmacı kuramla ilgili çalışan teorisyenler, bilimsel gerçeğin var olduğu ve bu gerçekliğin keşfedilmeyi-doğrulanmayı beklediği fikrini reddetmektedirler. Bilginin dışardan zihinlere aktarılamayacağı, bunun yerine bilginin bireylerin zihinlerinde şekillendiğini öne sürmektedirler (Schunk, 2004). Başka bir deyişle bilgi bireyin kendi yaşam deneyimlerine dayalı olarak oluşturulur (Fensham, Gunstone \& White, 1994; Driver ve diğ., 1994). Bunun bir sonucu olarak öğrenciler değişime dirençli ön bilgileri ile sınıfa gelirler, çünkü bu bilgiler bireyseldir, gerçek yaşam deneyimlerine dayalıdır ve bu 
nedenle de bunlarla ilişkili kavramlar öğrenilirken etkili olmaktadır. Bu yaklaşımda, yeni anlamların oluşturulması için eski ve yeni düşünceler arasında bağlantıların kurulması gerekmekte ve önceki bilgiler yeni bilginin algılanmasında belirleyici özelliğe sahip olmaktadır (Olkun \&Toluk, 2003). $\mathrm{Bu}$ nedenle öğretmenlerin görevi öğrencilerin alternatif kavramsallaştırmaları üzerinde düşünmelerini sağlayarak dünyayı daha iyi anlamlandırmalarına yardımcı olmaktır (Carr ve diğ., 1994).

Yapılandırmacı görüşe göre öğrenme fiziksel ve sosyal ortamda gerçekleşir. Sosyal ortamın öğrenmeye ve gelişime yardımcı olduğu Vygotsky'nin sosyokültürel kuramında da vurgulanmaktadır. Uno (1999) ise, yapılandırmacı kuramda öne sürülen öğrenme ilkelerini şöyle belirlemiştir.

1. Öğrenci, öğrenilecek içeriği/materyali önemli olarak algılamalıdır.

2. Öğrenci birçok şekilde bilgiyle derinlemesine meşgul olmalıdır.

3. Yeni öğrenilen bilgilerle önceden öğrenilen bilgilerin birbirleriyle ilişkili olması önemlidir.

4. Öğrenci yeni deneyimlerle anlayışını güncellemeli ve kontrol etmelidir.

5. Yeni öğrenilen bilgi otomatik olarak yeni durumlara transfer edilemez.

6. Öğrenme yeni bilgiyi pekiştirme ve kontrol etme stratejilerini de içeren bir süreçtir ve öğrenen ancak bunun farkına vardığında bağımsız bir ögrenen olabilir.

Yapılandırmacılığa göre hazırlanan eğitim programlarında önemli kavramların vurgulanması, her öğrencinin kendi gelişimine göre bu kavramları yapılandırması ve bu doğrultuda bir görüş geliştirmesi beklenmektedir. Öğretmen, dersin ana kaynağı olmaktan çıkıp, öğrenme sürecini denetleyen ve destekleyen bir kılavuz konumuna geçmiştir. Diğer bir deyişle, öğretmen ve öğrenci arasında geleneksel anlatma- dinleme ilişkisinin yerini daha karmaşık ve etkileşimli bir ilişki almıştır (Prawat, 1992).

Airasian ve Walsh (1997) yapılandırmacı bir öğrenme sürecinde öğretmenlerin rehberlik yapmayı, öğrencilerin kendi anlamlarını oluşturmaları için gerekli olan ortamı oluşturmayı, öğrencilerin farklılıklarını kabul ederek onlardan tek doğru cevabı beklememeyi, katı kriterlere ya da standartlara bağlı kalmadan, açık, özgür, bireysel sorumluluğu öne çıkaran 
bir ortam yaratarak öğrencileri öğrenmeye yönlendirmeyi ön plana çıkarmaları gerektiğini belirtmektedirler.

Böyle bir yaklaşım ölçme ve değerlendirme sisteminde de önemli değişimleri gündeme getirmiştir. Buna göre, öğretme-öğrenme sürecinde ortaya çıkan ürünleri değerlendirmek için sürecin içine yerleşmiş bir değerlendirme anlayışı benimsenmiştir. Öğrencinin sadece öğrenme sürecinin sonunda hangi noktada olduğunu belirlemek yerine, süreç boyunca neleri, nasıl yaptığını değerlendirmek ve bunu yaparken de farklı ölçme araçlarını kullanmak (öğrenci ürün dosyaları, kavram haritaları, öğretmen gözlemleri, projeler, bireysel ve grup değerlendirme, akran değerlendirme vb.) söz konusudur. Değerlendirme bilginin yanısıra tutum, araştırma, sorgulama, problem çözme vb. gibi değerli öğrenme ürünlerine de odaklanmaktadır (Duit \& Treagust, 1995; Welch, 1995; Bauer, 1999; Sherman, 2000; Windschitl, 2002).

Windschitl (2002), bir yapılandırmacı sınıfta öğretmen ve öğrenci etkinliklerinin temel özelliklerini şöyle sıralamaktadır.

1. Öğretmen öğrenilecek konuyla ilgili öğrencilerin bilgi ve deneyimlerini belirler, daha sonra öğrenme ortamını öğrencilerin mevcut bilgilerini yeniden yapılandırmalarına ya da biçimlendirmelerine yardımcı olacak şekilde düzenler.

2. Öğrencilere karmaşık, anlamlı, problem temelli etkinlikler yapmaları için olanak yaratır.

3. Öğrencilerin öğrenmelerine yardımcı olacak çeşitli bilgi kaynakları ve araçlar (teknolojik ya da kavramsal) sağlar.

4. Öğrencilerle birlikte çalışır ve verilen öğrenme görevi ile ilgili olarak öğrencilerin birbirleriyle iletişim kurmalarına destek verir.

5. Öğretmen kendi düşünme sürecini ortaya koyar ve öğrencilerini de konuşarak, yazarak, çizerek ya da başka biçimlerde kendi düşüncelerini ifade etmeye teşvik eder.

6. Öğrencilerden önceden belirlenmiş doğru cevaba odaklanmalarını istemek yerine, onlardan bilgiyi farklı ve gerçek ortamlara uygulamalarını, fikirleri açıklamalarını, metinleri yorumlamalarını, olayları tahmin etmelerini ve kanıtlara göre tartışmalarını ister.

7. Öğrencileri yukarıda sıralanan durumlarla bağlantılı olarak yansıtıcı ve bağımsız düşünmeleri yönünde teşvik eder. 
8. Öğrencilerin düşüncelerinin nasıl geliştiğini anlamak ve onlara sadece düşüncelerinin sonuçlarını değil, süreç hakkında da geribildirim vermek üzere çeşitli ölçme stratejileri kullanır.

Yapılandırmacı yaklaşımın öğretmene ve öğrenciye yüklediği bu yeni rolleri bilmek kadar bu rollerin öğrenme ortamına nasıl yansitılacağı da önemli bir konudur. Bu noktada, yapılandırmacı yaklaşıma çeşitli eleştiriler yöneltilmektedir. Bunlardan ilki yapılandırmacılığın öğrenmeyi açıklayan bir kuram olması ve öğrenmeye ilişkin bu bilgilerin öğretme -öğrenme sürecine yansitılmasının zor ve sorunlu olmasidır (Cobb, Yackel \& Wood, 1988; Smerdon, Burkam \& Lee, 1999). Başka bir deyişle yapılandırmacılığı tanıtan, açıklayan birçok çalışma ya da araştırmada öğretmenin sınıf içinde yerine getirmesi gereken sorumluluklar birer slogan olarak (rehber, yardımc1 araştırmacı, öğrencilerle birlikte öğrenen, ortam oluşturan vb.) açılanmakta, ancak bunun uygulamadaki anlamı geleneksel uygulamalarla öğretmeöğrenme sürecini yöneten birçok öğretmen için yeterince somut olmamaktadır (Windschitl, 2002).

Diğer taraftan yapılandırmacı yaklaşıma göre, öğrenme sürecinin planlanması ve uygulanmasının zaman alıcı olduğu ve eğitim sistemlerinin mevcut yapısıyla bu tür uygulamaları tam olarak gerçekleştirmenin zor olduğu yönünde de çeşitli eleştiriler yapılmaktadır (Talbert \& Mc Laughlin, 1993). Bu yaklaşıma göre planan bir öğrenme sürecinde zaman yönetimi, sınıfı yönetimi ve ölçme -değerlendirme öne çıkan başlıca sorunlar olarak sıralanmaktadır (Harwell, 2000).

\section{Program Reformunda Öğretmenler Tarafından Yanlış Anlaşılabilecek Konular}

Yeni programların uygulanması ile ilgili tartışmalarda en dikkat çeken nokta daha önce de belirtildiği gibi öğretmenlerin bu süreçte yeterince bilgilendirilmemiş olmasıdır. Pilot uygulamanın gerçekleştirildiği dokuz ilden toplam 120 okulun öğretmen ve okul müdürleri onar günlük bir hizmet içi eğitimden geçirilmiş ve bu süreçte hazırlanan yeni programların tanıtımları yapılmıştır. Ayrıca, pilot uygulama sürecinde Talim ve Terbiye Kurulu'nun internet sitesinde öğretmenlerin yaptıkları örnek uygulamalar ve geliştirdikleri etkinlikler paylaşıma açılmıştır. Öğretmenlere yönelik hizmet içi eğitim çalışmalarına yıl boyunca devam edilmiş, diğer taraftan tüm ilköğretim müfettişlerinin de bu eğitimi almaları sağlanmıştır. Bir taraftan reformla ilgili hizmet içi eğitimler sürdürülürken diğer taraftan pilot illerdeki uygulamalar il bazında yapılan toplantılarla değerlendirilmiştir.

2005-2006 öğretim y1lında yeni programların Türkiye genelinde uygulanmasına başlanmadan önce ilköğretim müfettişleri tarafından 
ilköğretim okullarında öğretmenlere kısa süreli seminerler verilmiş ve bu yolla onların yeni öğretim yılına hazırlanmaları amaçlanmıştır. Ancak eğitim sisteminde yapılması istenen bu değişimlerin öğretmenlere verilen bu kısa süreli seminerlerle ya da tanıtım toplantıları ile gerçekleşmesini beklemek hatalı olacaktır. Bu seminerleri veren ilköğretim müfettişlerinin de kısa süreli bir hizmet içi eğitim aldığı düşünülürse, onların da bu yaklaşımı tam olarak anladıklarını ve bunu öğretmenlere etkili bir şekilde açıklayabildiklerini düşünmek olanaklı görünmemektedir. Bir başka nokta ise, yeni programların tanıtımı için yapılan hizmet içi eğitim faaliyetlerinde anlatan merkezli bir anlayışın benimsenmiş olmasıdır. Yani öğrenen merkezli bir program öğretmen merkezli bir anlayıșla tanıtılmıștır. Bu durum aslında program değişim sürecinde görev alanlanların da bu yaklaşımı tam olarak içselleştiremediklerini düşündürmektedir. Sonuç olarak arzu edilen değişimlerin tahmin edilenden daha zor olacağı ve daha uzun zaman alacağı söylenebilir.

Bir çok Avrupa ülkesi öğretmenlerini reformun gereklerine göre yetiştirmede ve reform anlayışı doğrultusunda onların yeni rollerine uyum sağlamalarına yardım konusunda sıkıntı yaşamaktadır. Bu süreçte bir çok ulusal ve uluslararası projeler yapılmakta ve soruna ortak çözüm yolları aranmaktadır (Pinto, 2004). Başlatılan değişimin kısa zamanda tamamlanamayacağını ve en az beş yıllık bir süreye ihtiyaç duyulduğu MEB yetkililerince de belirtmektedir. Ancak, bu süreçte öğretmen eğitimi ile ilgili olarak uzun vadede nasıl bir politika izleneceği, hangi çalışmaların nasıl yapılacağı kamuoyuna net olarak sunulmamıştır. Bu noktada Talim ve Terbiye Kurulu eski başkanının şu açıklaması dikkat çekmektedir:

"Biz bunu bir yıllık bir proje olarak düşünmüyoruz. Beş yıllık çalışma içinde düşünüyoruz. Beş yıl boyunca öğretmenlerimiz hizmet-içi eğitimle, interaktif televizyon çalışmalarıyla, uzaktan öğretim metodlarıyla, eöğrenme kanalı ile, yüz yüze hizmet içi eğitim çalışmaları ... yaparak bu çalışmaları tamamlayacaklar. Diğer yandan ben öğretmenlerimizin yeni metodolojiye uyumu ile ilgili olarak çok da fazla sıkıntı görmüyorum. ... Çünkü bizim öğretmenlerimiz çok zor ve olumsuz şartlara bile kolayca uyum sağlayabilecek beceri gösteriyorlar. Eğer öğretmenlerimiz bu konuları hiç bilmiyor denilirse ve nasıl yapacakları konusunda bir endişe olursa, bu bence hiç sağlıklı değil, bizim öğretmenlerimiz zannedildiğinden çok daha fazla beceriye sahipler"'(Selçuk, 2004, s. 11).

Öğretmenlerimizin zor koşullarda çalışmaları ve zor koşullara uyum sağlama yeteneklerinin olması, onların bu anlayışın gereklerini doğru şekilde yerine getireceklerini göstermez (Bıkmaz, 2005). Yeterli eğitim desteğini alamayan ve kendilerinden önemli görevler beklenen ilköğretim 
öğretmenlerinin -özellikle de sınıf öğretmenlerinin- arzulanan değişimi sınıflarına yansıtabilmeleri için öncelikle değişimin kavramsal alt yapısını bilmek durumundadırlar. Kısa bir süre içinde onlarca yeni kavramla karşı karşıya kalan öğretmenlerin bazı sıkıntılar yaşamaları doğal karşılanmalıdır. Aşağıda program değişim sürecinde adeta birer slogan gibi sıkça tekrarlanan ve ögretmenler tarafından yanlış anlaşılmaya neden olabilecek bazı konular ele alınmıştır. Bunlardan ilki bireysel farklılıklarla ilgilidir.

Bireysel farklılıkları dikkate almak sadece yöntem zenginliği ile sağlanmaz.

Yeni öğretim programlarında "öğretme-öğrenme sürecinde öğrencilerin bireysel farklılıkları dikkate alınmalıdır" ifadesi sıkça yer almaktadır. Bireysel farklılıkları dikkate almak demek sadece öğretme-öğrenme sürecinde farklı yöntem, teknik, strateji kullanmak ya da farklı etkinlikler yapmak değil, aynı zamanda öğrencilerden beklentilerimizi de farklılaştırmak anlamına gelmektir.

Öğrenci merkezli eğitimin en önemli vurgularından birisi öğrencilerin bireysel olarak farklı ön bilgi, inanç ve deneyimlerle öğrenme sürecine katıldıkları ve bu nedenle yöntem, strateji ve materyallerin çeşitlendirilmesi gerektiğidir (APA, 1997). Diğer taraftan, öğrenciler öğretim sırasında aynı öğrenme deneyimini yaşasalar bile, sahip oldukları önceki bilgilerin ve geçmişte yaşamış oldukları deneyimlerin farklılığı nedeniyle bu yeni deneyime birebir aynı anlamı veremeyecekler ya da bu deneyimi aynı biçimde yorumlamayacaklardır (Deryakulu, 2000). Bu nedenle, öğrencilerin bireysel farklılıklarına göre onlardan beklenen ürün de farklı olmalıdır (Alesandrini \& Larson, 2002). Gerek programda gerekse öğretmenler için hazırlanan kılavuz kitaplarda öğretmenlere bu konuda gerekli rehberlik yapılamamıştır.

\section{Etkin öğrenme sadece etkinlik yapmak değildir.}

Yeni öğretim programlarında öğrencilere kazandırılmak istenen bilgi, beceri, tutumlar ve bunları öğrencilere kazandırmak için uygulanabilecek örnek etkinlikler verilmiştir. Program bu yapısı ile etkinlikleri ön plana çıkarmıştır. Bugüne kadar geleneksel sisteme göre ders işleyen öğretmenler etkin öğrenme sürecinde anlatımın hiç yapılmayacağını ve belirlenen kazanımlara sadece etkinlik yaparak ulaşılabileceğini düşünebilirler. Ancak öğretmen etkin öğrenme sürecinde gerekli gördüğü durumlarda anlatım yöntemini kullanabilir.

Ayrıca öğretmenler yeni programların yapısına bakarak öğretmeöğrenme sürecinde kazandırmayı planladıkları kavram/temalardan çok 
bunlarla ilgili etkinliklerin belirlenmesini başlangıç noktası olarak alabilirler. Seçilen ya da geliştirilen etkinliklerin sınıfta belirlenen sırayla yapılmasını yapılandırmacı yaklaşıma uygun bir süreç olarak düşünebilirler. Ancak süreçte yapılan etkinliklerin temel hedefi belirlenen tema ya da kavramın daha iyi öğrenilmesine yardımcı olmaktır.

$\mathrm{Bu}$ reform hareketini daha önce başlatmış olan birçok ülkede de yaşanmış ve halen yaşanmakta olan bir durumdur. Alesandrini \& Larson (2002) ile Windschitl (2002) öğretme-öğrenme sürecinde gerçekleştirilen etkinliklerde, bu etkinliklerin arkasında yatan fikrin yani amacının çoğu kez ihmal edildiğini belirtmektedirler. Örneğin, fen dersinde bir öğretmen öğrencilerinden okulun bahçesinde ya da yakın çevrede yaşayan hayvanların yaşam alanları ile ilgili bir araştırma yapmalarını ve bunu sınıfta sunmalarını isteyebilir. Ancak sunu sırasında yapılan araştırma ile öğrencilere kazandırılmak istenen ana fikir tartışılmazsa yapılan etkinlik anlamını yitirecektir. Bu tür uygulamalar ise, program reformu ile öne çıkarılan bir çok beceriyi - problem çözme, eleştirel düşünme, yaratıcı düşünme, iletişim, araştırma-sorgulama, bilgi teknolojilerini kullanma, girişimcilik, Türkçe'yi doğru, etkili ve güzel kullanma becerisi- geliştirmede yetersiz kalacaktır.

Etkin öğrenme, öğrencilerin öğretme-öğrenme sürecinde sadece fiziksel ya da sosyal anlamda etkin olmaları değildir .

Etkin öğrenmede öğrencinin öğrenme sürecine etkin katılımı söz konusudur. Zihinsel anlamda öğrenciyi harekete geçirecek her etkinlik (bireysel ya da grup çalışması, fiziksel ya da zihinsel katılım gerektiren) etkin öğrenmeyi sağlayacaktır. Bu nedenle sınıf içinde gerçekleştirilecek etkinliklerde öğrencilerin zihinsel olarak etkin olmalarına önem verilmesi, onlarda üst düzey düşünme becerilerinin gelişimi için önemlidir. Bunun için fiziksel olarak öğrencileri harekete geçirecek model tasarlama, drama, grafik oluşturma, deney yapma vb. birçok etkinlik yanında onları sadece zihinsel olarak harekete geçirecek etkinlikler de (metin ya da resimlerden çıkarım yapma, deney tasarlama, , hikayeye isim bulma, problem oluşturma, oyun tasarlama vb.) öğrencileri öğrenme sürecinde etkin kılacaktır.

Bu program anlayışında öğretmen güçlï bir alan bilgisine ihtiyaç duyacakttr.

Yeni program anlayışında öğretmen, öğretme-öğrenme sürecini yönlendiren, öğrenciye rehber olan ve etkili bir öğrenme ortamı hazırlayan kişi olarak tanımlanmaktadır. Bu sorumlulukları etkili bir şekilde yerine getirebilmek için öğretmen düşünülenin aksine güçlü bir alan bilgisine ihtiyaç duyacaktır (Windschitl, 2002; Verspoor,1989). 
Yapılandırmacı yaklaşımda, öğrencilerin problem çözme, araştırma, model ya da tasarım oluşturma gibi bir çok etkinliği bizzat gerçekleştirmeleri beklenmektedir. $\mathrm{Bu}$ tür etkinliklerin gerçekleştirilmesinde öğretmenlerin güçlü bir alan bilgisine ihtiyaç duyacağı açıktır. Örneğin; öğrencilerin bireysel ya da grup olarak yapacakları farklı proje çalışmalarına destek olabilmek ve bu süreçte onlara yol gösterebilmek için o konuyla ilgili iyi bir alan bilgisi gerekmektedir.

Alan bilgisi yetersiz olan öğretmelerin öğretimle ilgili tercihlerinde daha az esnek oldukları ve daha çok didaktik yöntemleri tercih ettikleri (Mc Laughlin \& Talbert, 1993) ve öğrenci merkezli uygulamalara uygun bir öğretme-öğrenme süreci tasarlama ve bunu hayata geçirmede sıkıntı yaşadıkları görülmektedir (Elmour, Peterson \& McCarthey, 1996).

Yeni programlarda ölçme ve değerlendirmede yeni tekniklerin yanında geleneksel ölçme ve değerlendirme teknikleri de kullanılabilir.

Öğretmenler yeni programların ölçme ve değerlendirme anlayışında geleneksel ölçme ve değerlendirme yaklaşımların hiç yerinin olmadığını düşünülebilirler. Yeni programların ölçme ve değerlendirme konusundaki vurgusu, öğrenme sonucunu belirleme anlayışından çok öğrenme sürecinde öğrencinin neleri kazandığını belirlemeye doğru kaymıştır. Ancak bu geleneksel ölçme tekniklerinin hiç kullanılmayacağı ve öğrenme sürecinin sonunda hiç değerlendirme yapılmayacağı anlamına gelmemektedir. Yanlızca geleneksel tekniklerle yapılan ölçme ve değerlendirmelerin öğrencilerin gerçek başarılarını ortaya koyma da yetersiz olduğu ve daha çok bilgiyi ölçtüğü, öğrencilerin beceri ve tutumlarındaki gelişmelerin de bu sistemde ortaya konması (Duit \& Treagust, 1995; Welch, 1995; Bauer, 1999; Martin, 1997) ve böylece ölçme ve değerlendirme sisteminde farklı tekniklerin kullanılması gerekliliği gündeme gelmiştir.

Program reformu sürecinde öğretmenlerin belki de en büyük sıkıntıyı ölçme ve değerlendirme alanında yaşadıkları ve yaşayacakları söylenebilir. Nitekim, Gözütok ve diğg.'nin (2005) yaptığı bir araştırmada öğretmenlerin kendilerini en yetersiz gördükleri alanın ölçme değerlendirme olduğu ortaya çıkmıştır. Önerilen ölçme ve değerlendirme yaklaşımı ile öne çıkan teknikler (öğrenci ürün dosyası, kavram haritaları, gözlem, görüşme, performans değerlendirme, akran değerledirme, öz değerlendirme, proje değerlendirme, tutum ölçekleri, yapılandırılmış grid, dallanmış ağaç, venn şeması vb.) öğretmenlerimiz için oldukça yenidir. Her ne kadar programlarda bu yeni teknikler kısaca tanıtılsa da, uygulamada bu tekniklerin nasıl kullanılacağı, ne sıklıkta yapılacağı, nasıl puanlanacağı ve başarı notunun belirlenmesinde 
katkılarının ne olacağı gibi pek çok konu netlik kazanmamıştır. Bu konuda öğretmenler yalnız bırakılmıştır.

\section{Yeni program reformuyla öğretmenlerin iş yükü daha da artacakttr.}

Kalabalık sınıflar, yetersiz fiziki alt yapı, yetersiz eğitsel destek nedeniyle öğretmenlerin yeni program anlayışına göre öğretme-öğrenme sürecini planlama ve uygulama konusunda birçok güçlük yaşayacağı ve bu dönüşüm için uzun bir zamana ihtiyaç duyacağı açıkça anlaşılmaktır. Cohen (1988), bu süreçte öğretmenlerin daha fazla çalışmaları, konuya daha fazla odaklanmaları ve daha fazla eğitsel sorumluluk taşımaları gerektiğini belirtmektedir.Yeni ölçme ve değerlendirme anlayışının öne çıkardığı farklı eğitsel görevleri yerine getirme, ön bilgilere ve bireysel farklılıklara göre etkinlik temelli bir ögrretme-öğrenme süreci tasarlama ve bunu hayata geçirme konusunda öğretmenlerin daha planlı olmaları ve meslektaşları ile daha yakın bir işbirliği yapmaları zorunlu olmaktadır.

\section{SONUÇ}

Bu çalışma Türkiye'de 2005-2006 öğretim yılında ülke genelinde uygulanmasına başlanan yeni ilköğretim programlarında adeta birer slogan gibi sıkça tekrarlanan ve öğretmenler tarafından yanlış anlaşılmaya neden olabilecek bazı konuları belirlemek ve bunların neden yanlış anlaşılabileceğini gerekçeleriyle ortaya koymak amacıyla yapılmıştır. Bu konular arasında bireysel farklılıkları dikkate almak, etkin öğrenmenin anlamı, geleneksel ölçme değerlendirme yaklaşımlarının yeni programlardaki yeri, öğretmenlerin alan bilgisi ihtiyacı ve iş yüklerinin durumu ile ilgilidir.

Öğrencilerin düşünceleri ve kavramsallaştırmaları üzerinde önemle duran, etkinlik temeline dayanan, ortaya konan üründen çok öğrenme sürecinin vurgulandığı, kavramları ve temaları düșünme becerilerini geliştirmek için bir araç olarak kullanan ve dolayısıyla bireysel gelişim üzerinde odaklanan, ölçme ve değerlendirmenin öğretme-öğrenme sürecinin her aşamasında kullanıldığı, ölçme ve değerlendirme tekniklerinin daha gerçekçi ve çok yönlü olduğu bir program anlayışının benimsenmesi önemli bir girişimdir.

Ancak özellikle gelişmekte olan ülkelerde yapılan eğitim reformlarında bütün ilgi ve dikkatin daha çok değişim üzerine odaklandığı ve bu değişimin nasıl yapılacağı konusunun ihmal edildiği dikkat çekmektedir (Rogan \& Grayson, 2003). Bu tespit Türkiye için de geçerlidir. Değişimi gerçekleştirecek olan öğretmenlerin yeni programların uygulanması 
kousunda yeterince desteklenmedikleri ve bu konuda yanlız birakıldıkları görülmektedir (Gözütok ve diğ.,2005).

Oysa eğitim reformlarında başarı için öğretmenlerin değişime hazır olmaları, bu değişimin gerekli ve faydalı olacağına inanmaları gerekmektedir. Ayrıca öğretmenlerin öğretme-öğrenme konusundaki inançları da reformların ön gördüğü değişim için önemli bir aracı olmaktadır (Haney, Czerniak, Lumpe, 2003; Bybee, 1993; Cuban, 1990; Fullan \& Miles, 1993; Elkind, 2004). Aslında tüm uygulayıcıların reformu anlaması ve uygulamaya istekli olması reformun başarısı için tek başına yeterli değildir. Aynı zamanda uygulamada gerekli olacak yeni bilgi ve yeterliklere de sahip olmayı gerektirmektedir (Battista, 1994). Bu yeni bilgi ve yeterliklere sahip olmayan öğretmenlerin kendi bildikleriyle bu süreci yürütecekleri açıktır.

Program değişiminin istenilen düzeyde gerçekleştirilmesi için daha uzun soluklu, katılımcı ve ülkemizin gerçeklerine uygun bir öğretmen eğitimi -hizmet öncesi eğitimi de içine alacak şekilde- planlanmalı ve uygulanmalıdır. Bu süreçte mevcut hizmet içi eğitim uygulamalarının da ciddi olarak ele alınması ve daha verimli hale getirilmesi gerekmektedir. Yeni anlayış doğrultusunda yapılacak eğitim hizmetlerinde üniversitelerden yardım alınması kaçınılmazdır. Bu işbirliği ülkemiz koşullarında bir zorunluluktur. Eğitim hizmetleri öğrenen merkezli bir anlayışla verilmelidir. Öğretmen eğitimi konusunda gerekli önlemler alınmadığı ve öğretmenlerimize ihtiyaç duydukları destek verilmediği takdirde, sistemde yapılmaya çalışılan değişimin kağıt üzerinde kalacağı bir gerçektir. Bu süreçte okullarımızda çok şey değişecektir, ancak bu değişimin hedeflenen değişime ne kadar uygun olacağı ise tartışılacaktır. 


\section{KAYNAKLAR}

APA (1997). Learner-Centered Psychological Principles: A Framework for School Redesign and Reform [Online]: http://www.apa.org/ed/lcp.html adresinden 10 Ocak 2005 tarihinde indirilmiştir.

Airasian, P. W. \& Walsh, M. E. (1997). Constructivist caution. Phi Delta Kappan, 78, 444-449.

Alesandrini, K. \& Larson, L. (2002). Teachers bridge to constructivism. The Clearing House, 75(3), 118-122.

Battista, M. T. (1994). Teacher beliefs and the reform movement in mathematics education. Phi Delta Kappan, 75(6), 462-468.

Bauer, E. (1999). To promise of alternative literacy assessments in the classroom: A review of empirical studies. Reading Research and Instruction, 38, 153-168.

Bikmaz, F. ( Nisan 2005). “The Curriculum Reform Movement In Turkey: Missing Points In The Proposed Constructivist Framework". Paper presented at the annual meeting of the American Educational Research Association, Montreal, Canada.

Boyd, W. L. (2000). The "R's of school reform" and the politics of reforming or replacing public schools. Journal of Educational Change, $1(3), 225-252$.

Bybee, R. W. (1993). Leadership, responsibility, and reform in science education. Science Education, 2(1), 1-9.

Carr, M., Barker, B., Bell, B., Biddulph, F., Jones, A., Kirkwood, V., Pearson, J. \& Symington, D. (1994). The constructivist paradigm and some implications for science content and pedagogy. In P. J. Fensham, R. T. Gunstone \& R.T White (Eds), The content of science (pp. 147 160). London: The Falmer Press.

Cobb, P., Yackel, E. \& Wood, T. (1988). "Curriculum and teacher development as the coordination of pschological and antropological perspectives." Paper presented at the meeting of the Instruction/Learning Working Group of the National Center for Research in Mathematical Science Education, Madison,WI.

Cohen (1988), Educational technology and school organization.In R.S. Nickerson \& P. P. Zodhiates (Eds.), Technology in education: Looking toward 2020, Hillsdale, NJ:Lawrence Erlbaum. 
Cuban, L. (1990). Reforming again, again and again. Educational Researcher, 19(1), 3-13.

Deryakulu, D. (2000). Yapıcı öğrenme. A. Şimşek (Ed.) Sınıfta Demokrasi (s. 53-77). Eğitim- Sen Yayınları, Ankara.

Duit, R. \& Treagust, D. (1995). Students' conceptions and constructivist teaching. In. B. J. Fraser, and H. J. Walberg (Eds.), Improving science education (pp. 46-69). The National Society for the Study of Education.

Driver, R., Asoko, H., Leach, J., Mortimer, E. \& Scott, P. (1994). Constructing scientific knowledge in the classroom. Educational Researcher, 23(7), 5-12.

Elmour, R., Peterson, P. \& McCarthey, S. (1996). Restructuring in the classroom. San Francisco: Jossey-Bass.

Elkind, D. (2004). The problem with constructivism. The Educational Forum, 68(4), 306-312.

El-Sheikh Hasan, O. H. (2000). Improving the quality of learning: global education as a vehicle for school reform. Theory into Practice, 39(2), 97-104.

Enderlin-Lampe, S. (2002). Empowerment: teacher perceptions, aspirations and efficacy. Journal of Instructional Psychology, 29(3), 139-147.

Fensham, P. J, Gunstone, R. F. \& White, R. T (1994). Science content and constructivist views of learning and teaching. In P. J. Fensham, R. F. Gunstone \& R. T. White (Eds.), The content of science (pp. 1-8). London: The Falmer Press.

Flouris, G. \& Pasias, G. (2003). A critical appraisal of curriculum reform in Greece (1980-2002). European Education, 35(3), 73-90.

Fullan, M. C. \& Miles, M. B. (1993). Getting reforms right: What works and what doesn't. Phi Delta Kappan, 73(4), 745-752.

Gough, N. (1999). Globalization and school curriculum change: locating a transnational imaginary. Journal of Educational Policy, 14(1), 73-84.

Gözütok, D., Akgün, Ö. E. ve Karacaoğlu, Ö.C. (2005). Yeni ilköğretim programlarının uygulanmasına öğretmenlerin hazırlanması. 14-16 Kasım 2005 Eğitimde Yansımalar:VIII, Yeni İlköğretim Programlarını Değerlendirme Sempozyumu BildiriKitabı içinde: ss:17-41.Kayseri.

Haney, J. J., Czerniak, C. M. ve Lumpe, A. T. (2003). Constructivist beliefs about the science classroom learning environment: Perspectives from 
teachers, administrators, parents, community members, and students. School Science and Mathematics, 103(8), 366-378.

Harlen, W. (1997). Primary teachers' understandings in science and its impact in the classroom. Research in Science Education, 27(3), 323337.

Harwell, S. H. (2000). Impediments to changes: an application for forcefield analysis to leader master teacher training in an elementary level science systemic reform initiative. Journal of Elementary Science Education, 12(2), 7-19.

Labaree, D. F. (1999). The chronic failure of curriculum reform. Education Week, 18(36), 42-45.

Law, W. (2004). Translating globalization and democratization into local policy: Educational reform in Hong Kong and Taiwan. International Review of Education, 50(5-6), 497-524.

Marginson, S. (1999). After globalization: emerging politics of education. Journal of Educational Policy, 14(1), 19-31.

Martin,D. J. (1997). Elementary science methods: a constructivist approach. Delmar Publishers, New York.

Matthews, M. R. (1998). Introductory comments on philosophy and constructivism in science education. In Matthews, M. R.. (Ed.), Constructivism in science education; A philosophical examination. Dordrecht: Kluwer Academic Publications.

Mc Laughlin, M. \& Talbert, J. (1993). Context that matter for teaching and learning. Stanford, CA: Center for Research on the Context of Secondary School Teaching.

MEB. (1999). 2000 yılında milli eğitim. T.C. Milli Eğitim Bakanlığı. A.Ç.E.M ve 4. Akşam Sanat Okulu Matbaası. Ankara.

MEB. (2005). Illköğretim 1-5.sınıf programları tanıtım el kitabı. Milli Eğititm Müdürlüğü Basımevi, Ankara.

Olkun, S. \& Toluk, Z. (2003). Illköğretimde etkinlik temelli matematik öğretimi. Anı Yayıncılık, Ankara.

Pinto, R. (2004). Introduction curriculum innovation in science: Identifying teachers' transformation and design of related teacher education. Science Education, 1-18. 
Prawat, R. S. (1992). Teachers beliefs about teaching and learning: a constructivist perspective. American Journal of Education, 354-393.

Richardson, V. (1997). Constructivist teacher education. New York: Falmer Press.

Rogan, J. M. \& Grayson, D. J. (2003). Towards a theory of curriculum implementation with particular reference to science education in developing countries. International Journal of Science Education, 25 (10), 1171-1204.

Sani, J. M. (2000). The potentials and challenges of information and communication technologies for education: The training for teachers. In: Globalization and living together: The challenges for educational content in Asia, ed. by UNESCO, 29-31. Paris:UNESCO.

Schunk, D. H. (2004). Learning Theories: An Educational Perspectives. Fourth edition. New Jersey, Pearson Prentice Hall.

Selcuk, Z. (2004). Talim ve Terbiye Kurulu başkanı Ziya Selçuk'la söyleşi. Bilim ve Aklın Aydınlığında Ĕ̈itim, 5(54-55), 7-15.

Sherman, S. J. (2000). Science and science teaching: Science is something you can do. Boston, MA: Houghton Mifflin Company.

Simpson, T. L. (2002). Dare I oppose constructivist theory? The Educational Forum, 66, 633-662.

Smerdon, B. A., Burkam, D. T. \& Lee, V. E. (1999). Access to constructivist and didactic teaching: who gets it?, where is it practiced?, Teachers College Record, 101, 5-34.;

Talbert, J. E. \& Mc Laughlin, M. V. (1993). Understanding teaching in context. In D. K. Cohen, M.V. Mc Laughlin \& J.E. Talbert (Eds.), Teaching for understanding: Issues for policy and practice (pp.167205). San Francisco: Jossey-Bass.

Tsai, C. C. (1998). Science learning and constructivisim. Curriculum and Teaching, 13, 31-52.

Uno, G. E. (1999). Handbook on teaching undergraduate science course: A survival tarning manual. Forth Worth, TX: Harcourt Brace.

Welch,W. W. (1995). Student assessment and curriculum evaluation. In B. J. Fraser \& H. J. Walberg (Eds.), Improving science education (pp. 90116). The National Society for the Study of Education. 
Windschitl, M. (2002). Framing constructivism in practice as the negotiation of dilemmas: an analysis of the conceptual, pedagogical, cultural, and political challenges facing teachers. Review of Educational Research, 72(2), 131-175.

Verspoor, A. (1989). Pathways to change: Improving quality of education in developing countries. Washington DC: The World Bank.

Zajda, J. (2003). Educational reform and transformation in Russia. European Education, 35(1), 58-88. 